\title{
Knowledge, attitudes and practices of doctors at Jubilee Hospital, Tshwane District, regarding the syndromic management guidelines for sexually transmitted infections
}

\author{
Charles Uchenna and Indiran Govender*
}

Department of Family Medicine and Primary Health Care, Sefako Makgatho Health Sciences University, Pretoria, South Africa

*Corresponding author, email: indiran.govender@gmail.com

Background: Sexually transmitted infections (STIs) are a public health problem globally, but especially so in sub-Saharan Africa. They contribute significantly to the burden of disease in South Africa and are recognised as major contributors to the human immunodeficiency virus (HIV) epidemic, with other potential complications when not managed properly. First-line doctors play a critical role in the management of persons suffering from STIs, and need to comply with the national guidelines for STI management.

Aim: To determine the knowledge, attitudes and practices of doctors working in Jubilee District Hospital, Metsweding region, Tshwane, regarding the STI syndromic management (SM) guidelines.

Setting: Jubilee District Hospital in Tshwane North, Gauteng province, South Africa.

Methods: A cross-sectional, descriptive study using a self-administered questionnaire was conducted.

Results: Forty-three of the 50 doctors employed at the hospital participated in the study. Fourteen (32.6\%) of the doctors were in the 36-40-year age group. Most of the doctors (36 or $83.7 \%$ ) had only the basic bachelor's degree, and only 4 (9.3\%) attended additional STI training. Only 2 respondents (4.6\%) had correct knowledge concerning management of male urethritis syndrome and 10 (23.3\%) regarding management of genital ulcer syndrome. In compliance with the national SM guidelines for STls, 22 (52.4\%) of the doctors said they made a diagnosis of STIs using history and physical examination. Only 7 (16.7\%) said they asked their patients during every consultation about the number of sexual partners, 21 (51.7\%) said they always counsel/ screen patients with STIs for HIV infection, and only $4(9.5 \%)$ said they always filled in partner notification slips after attending to the index patient with STIs. This study demonstrated a relationship between doctors' knowledge of the SM guidelines for STIs and their age.

Conclusion: Overall the knowledge and practices of doctors at Jubilee District Hospital were suboptimal, and training on the SM of STIs should be made available to address this. Management should introduce regular monitoring, evaluation and supportive services for the doctors regarding their management of STIs according to the guidelines.

Keywords: guideline adherence, HIV/AIDS, male urethritis syndrome, primary health care doctors, STI guidelines

\section{Introduction}

Sexually transmitted infections (STIs) remain a major public health problem in most parts of the world, including South Africa $(\mathrm{SA}) .^{1}$ According to the World Health Organization (WHO) approximately 92.6 million new cases occur annually in Africa (WHO, 2012), and about 11 million new STI infections occur annually in South Africa. ${ }^{3}$ Approximately 96 cases of STIs are managed monthly at Jubilee Hospital. ${ }^{4}$

Failure to correctly treat STIs early may result in serious complications, especially in women and newborn children. STIs can also cause relationship disharmony if one partner is infected. ${ }^{5}$ Other than the direct effect of STIs and possible complications such as infertility, urethral stricture, ectopic pregnancy, low birthweight, stillbirth, spontaneous abortion, cervical cancer, ophthalmia neonatorum and congenital infections, the worst consequence is perhaps the increased risk of transmission of HIV infection. ${ }^{6-8}$

With the emergence of HIV and AIDS it has become more difficult to distinguish aetiological causes of STIs. A syndrome-based approach to their management has therefore been developed and promoted in countries with a high HIV prevalence. ${ }^{8}$ The syndromic approach enables healthcare providers to make a diagnosis within a short time without special skills and sophisticated laboratory investigations.

Syndromic management (SM) is based on the premise that there is a strong correlation between syndromes and the presence of a particular disease. ${ }^{9}$ The South African national STIs treatment guideline for control and management of STIs was introduced in 1990 and is available at all primary health care facilities. Comprehensive SM of STIs includes the use of adequate and appropriate medication, active condom promotion, effective partner treatment and risk-reduction counselling for STIs and HIV. ${ }^{2}$

Many studies have demonstrated the positive impact of SM on the incidence of STIs and HIV in a given population, but the knowledge of the SM guidelines amongst doctors is suboptimal, especially amongst those without formal STI training. ${ }^{10}$ There is also evidence that doctors do not always adhere to national treatment guidelines. ${ }^{11}$

This study sought to determine the knowledge, attitudes and practices of doctors regarding syndromic STI management guidelines at Jubilee Hospital. 


\section{Methodology}

\section{Study design}

This was a descriptive cross-sectional study using self-administered questionnaires.

\section{Study population and setting}

All doctors working at Jubilee District Hospital from October 1, 2014 to February 28, 2015 were included in the study. Jubilee District Hospital is situated in the northern part of Tshwane district in Gauteng province and has 551 beds. ${ }^{12}$

\section{Sample size}

Epi Info ${ }^{\mathrm{TM}}$ (CDC, Atlanta, GA, USA) was used to calculate a significant sample size. This was calculated to be 34 of the 51 doctors, at a $95 \%$ confidence interval and a standard error of $10 \%$.

\section{Data collection}

Data were collected using self-administered questionnaires in English. A pilot study was performed using five doctors at a different district hospital, which showed that the respondents understood the questions, and that on average it took 15 minutes to complete the questionnaire.

\section{Data analysis}

The data were captured on a Microsoft Excel $^{\oplus}$ (Microsoft Corp, Redmond, WA, USA) spreadsheet. Data capturing was verified and validity checks were performed as part of the data cleaning process. The primary endpoint was the percentage adherence to the South African national STI guidelines. Adherence was calculated as outlined below.

The guidelines were listed and each participating doctor was assessed to ascertain whether he/she follows the guidelines. The total number of guidelines followed by a doctor was added up and converted to a percentage of the total number of guidelines. Basic descriptive statistical measures were calculated for the percentage adherence scores. A 95\% confidence interval was calculated for the mean percentages.

All statistical procedures were performed on Statistical Analysis System (SAS) Release 9.2 or higher (SAS Institute, Cary, NC, USA), running under Microsoft ${ }^{\circledR}$ Windows 7 for a personal computer.

To overcome participant (subject) bias, multiple-item tests were used so that random participant errors would tend to balance out. Clear instructions were given before the test questions to avoid any participant misunderstanding. All participants were directly observed filling in the questionnaires to get a true reflection of their knowledge and practices of the STI guidelines.

\section{Ethical considerations}

Ethical clearance was obtained from the Sefako Makgatho University Research Ethics Committee (MREC/M/212/2013: PG) and Tshwane/Metsweding Regional Research Ethics Committee. Permission to conduct the study was obtained from the management of Jubilee District Hospital. Informed consent was obtained from all participants. Confidentiality and anonymity were maintained.

\section{Results}

\section{Demographic information}

Forty-three doctors participated in the study, of whom 23 were male and 20 were female (Table 1).

\section{Knowledge of STIs and SM of common STIS}

The majority of the respondents (39 or $90.7 \%$ ) had heard of the SM guidelines for STIs, and many of the doctors (17 or $39.5 \%$ ) got their information on STIs from medical books. Only 4 (9.3\%) of the respondents had not heard of the different STI syndromes. Over $50 \%$ of the respondents (22) felt the risk for acquiring STIs to be highest in the 26-38-year age group (Table 2).

Table 3 shows that majority of the respondents (34 or $79.1 \%$ ) have moderate knowledge of organisms that cause STIs, while 19 (44.2\%) of the respondents had high knowledge of STI syndrome abbreviations.

Table 4 shows that the majority of the respondents ( 29 or $67.4 \%$ ) did not know the correct specific organisms causing painful scrotal swelling.

\section{Doctors' knowledge of SM of male urethritis syndrome (MUS)}

Table 5 shows that only 2 respondents (4.6\%) gave correct answers with regard to the pharmaceutical management of MUS, and 10 (23.3\%) respondents gave the correct answer for management of genital ulcer syndrome (GUS), whilst only 3 respondents $(6.98 \%)$ gave correct drug names, dose, frequency and duration used to treat GUS.

Table 6 shows that the majority ( 25 or $61 \%$ ) of the respondents considered the mass media to be the most effective source of information with regard to STI control.

Table 1: Baseline characteristics of the participants

\begin{tabular}{|c|c|c|}
\hline Characteristics & Frequency $(n=43)$ & Percentage (\%) \\
\hline \multicolumn{3}{|l|}{ Sex: } \\
\hline Male & 23 & 53.5 \\
\hline Female & 20 & 46.5 \\
\hline \multicolumn{3}{|l|}{ Age group (years): } \\
\hline $25-30$ & 13 & 30.2 \\
\hline $31-35$ & 8 & 18.6 \\
\hline $36-40$ & 14 & 32.6 \\
\hline Above 40 & 8 & 18.6 \\
\hline \multicolumn{3}{|c|}{ Age: Mean $=35.3$ SD $=6.18$ Median $=36$ Min. $=25$ Max. $=48$} \\
\hline \multicolumn{3}{|l|}{ Marital status: } \\
\hline Living together & 5 & 11.6 \\
\hline Married & 26 & 60.5 \\
\hline Single & 12 & 27.9 \\
\hline \multicolumn{3}{|l|}{ Education: } \\
\hline Bachelor's degree only & 36 & 83.7 \\
\hline Master's & 3 & 7 \\
\hline Additional qualification(s) & 4 & 9.3 \\
\hline \multicolumn{3}{|l|}{ Years of practice: } \\
\hline$<5$ & 12 & 27.9 \\
\hline $6-10$ & 17 & 39.5 \\
\hline $11-15$ & 14 & 32.6 \\
\hline
\end{tabular}


Table 2: Knowledge of the SM guidelines for STIs

\begin{tabular}{|c|c|c|}
\hline Factor & $\begin{array}{l}\text { Frequency } \\
\quad(n=43)\end{array}$ & $\begin{array}{l}\text { Percentage } \\
(\%)\end{array}$ \\
\hline \multicolumn{3}{|c|}{$\begin{array}{l}\text { Have you previously heard of STI } \\
\text { guidelines? }\end{array}$} \\
\hline Yes & 39 & 90.7 \\
\hline No & 4 & 9.3 \\
\hline \multicolumn{3}{|c|}{ Period when heard of STIs $(n=29)$ : } \\
\hline During medical school & 11 & 37.9 \\
\hline Post-medical school & 18 & 62.1 \\
\hline \multicolumn{3}{|c|}{$\begin{array}{l}\text { Source of knowledge of the SM } \\
\text { guidelines: }\end{array}$} \\
\hline Radio & 1 & 2.3 \\
\hline Medical textbooks & 17 & 39.5 \\
\hline Seminar & 4 & 9.3 \\
\hline Medical journal & 10 & 23.3 \\
\hline Colleague & 14 & 32.6 \\
\hline Other & 4 & 9.3 \\
\hline \multicolumn{3}{|c|}{$\begin{array}{l}\text { Have knowledge of the different } \\
\text { STI syndromes: }\end{array}$} \\
\hline Yes & 39 & 90.7 \\
\hline No & 4 & 9.3 \\
\hline \multicolumn{3}{|c|}{ Knowledge of the age group at highest risk for STIs: } \\
\hline Youth (13-25 years) & 21 & 48.8 \\
\hline Adult (26-38 years) & 22 & 51.2 \\
\hline
\end{tabular}

\section{Doctors' attitudes to SM of STIs}

When asked about the current SM guidelines, five (12.8\%) of the respondents were not satisfied with the SM guidelines but did not give reasons for their dissatisfaction. Only three $(7.1 \%)$ of the respondents were not interested in attending continuing medical education seminars on STIs (Table 7).

\section{Doctors' practices with regard to SM of STIs}

The syndromic approach recommends use of only history and physical examination for diagnosis of the STI syndromes. Twenty (47.6\%) of the respondents made the diagnosis of STIs based on clinical evaluation and microscopy and/or culture. Seven (16.7\%) doctors asked about the number of sexual partners during all their consultations. Only $23(54.8 \%)$ of the respondents asked all patients suffering from STls about their number of sexual partners, while only 21 (51.2\%) examined the genital area of every patient suffering from STIs (Table 8).

\section{Comparison of doctors' knowledge, attitudes and practices and their sex and age}

There was no difference between male and female doctors regarding their knowledge, attitudes and practices of SM of

Table 3: Knowledge of the organisms causing STIs and syndrome abbreviations

\begin{tabular}{lccc}
\hline $\begin{array}{l}\text { Knowledge } \\
\text { question }\end{array}$ & $\begin{array}{c}\text { High } \\
\text { (scores of } \\
\mathbf{8 - 1 0 )}\end{array}$ & $\begin{array}{c}\text { Moderate } \\
\text { (scores of } \\
\mathbf{5 - 7 )}\end{array}$ & $\begin{array}{c}\text { Low } \\
\text { (scores of } \\
\mathbf{0 - 4})\end{array}$ \\
\hline $\begin{array}{l}\text { Doctors' knowledge } \\
\text { of organisms } \\
\text { causing STls }\end{array}$ & $0(0 \%)$ & $34(79.1 \%)$ & $9(20.9 \%)$ \\
$\begin{array}{l}\text { Doctors' knowledge } \\
\text { of STI syndrome } \\
\text { abbreviations }\end{array}$ & $19(44.2 \%)$ & $17(39.5 \%)$ & $7(16.3 \%)$ \\
\hline
\end{tabular}

STIs. Younger doctors had better knowledge of the SM guidelines for STls compared with older doctors ( $>40$ years) (Table 9 ).

\section{Discussion}

The response rate of $84.3 \%$ reflects the high interest that these doctors have in STI management.

\section{Doctors' knowledge of the STI guidelines}

In general there was suboptimal knowledge amongst the respondents regarding the SM of STIs. These results are comparable to those of several studies done in South Africa and the rest of Africa. In KwaZulu-Natal, South Africa, only $9 \%$ of doctors knew the STI guidelines, in $18 \%$ of cases dose or duration of drugs was inadequate, while in $73 \%$ of cases incorrect drugs were prescribed. ${ }^{13}$

Knowledge of the clinicians at Jubilee District Hospital was dependent on the syndrome type and the clinician's age. Respondents had better knowledge of the causative organisms and SM for mucopurulent discharge of the cervix/urethra (39 or $95.1 \%$ ) and genital ulcers (37 or $86 \%$ ) compared with other STI syndromes. The reason for this may be because these conditions are those most frequently encountered in this setting. ${ }^{14}$

Only $23.3 \%$ of respondents reported prescribing the correct management for GUS in those who have not been sexually active in the past three months, while $11.6 \%$ prescribed the correct management for those who had been sexually active in the past three months. Genital ulcers are difficult to distinguish clinically, and in the absence of laboratory diagnosis it therefore makes sense to use SM. ${ }^{15,16}$ Similarly, a study in Namibia showed that doctors in general did not give quality care to patients presenting with genital ulcers. None of these doctors could treat genital ulcer correctly as per the syndromic approach. ${ }^{17}$

In a study conducted across six West African countries the doctors provided a low quality of STI management. ${ }^{18}$ In $35.3 \%$ of cases healthcare providers made the correct diagnosis according to national STI syndromic algorithms, while effective treatment was given in only $14.1 \%$ of cases. Only $19.5 \%$ of the patients were advised to use condoms and $50.8 \%$ of patients were advised to tell their partners to seek treatment. ${ }^{18} \mathrm{~A}$ study in Gamo Gofa zone, Ethiopia found that the knowledge and practice of SM of STIs by clinicians in that area were poor. Only in $8.3 \%$ of cases did the clinicians follow the national guidelines correctly and treat the patient correctly using the SM approach. $^{19}$

Knowledge of SM of STIs was statistically lower $(p=0.005)$ among doctors who were more than 40 years of age (older doctors). Training should therefore target older doctors, i.e. those who qualified before 1992. A possible explanation for this finding could be that most of the respondents in this age group

Table 4: STI syndromes and causative organisms

\begin{tabular}{|c|c|c|}
\hline $\begin{array}{l}\text { Specific STI syndrome and responsible } \\
\text { causative organism(s) }\end{array}$ & Correct & Incorrect \\
\hline Causes of genital ulcers $(n=43)$ & $37(86.0 \%)$ & $6(14.0 \%)$ \\
\hline Causes of vaginal discharge $(n=41)$ & $39(95.1 \%)$ & $2(4.7 \%)$ \\
\hline Cause of painful scrotal swelling $(n=43)$ & $14(32.6 \%)$ & $29(67.4 \%)$ \\
\hline $\begin{array}{l}\text { Causes of mucopurulent discharge of the } \\
\text { cervix/urethra }(n=43)\end{array}$ & $39(90.7 \%)$ & $4(9.3 \%)$ \\
\hline
\end{tabular}


Table 5: Knowledge of the SM of MUS and GUS

\begin{tabular}{|c|c|c|c|c|}
\hline \multirow[b]{2}{*}{ MUS } & & \multicolumn{3}{|c|}{ Name of drug } \\
\hline & & Cefixime $n(\%)$ & Doxycycline $n(\%)$ & Metronidazole $n(\%)$ \\
\hline & Correct & $7(16.3)$ & $27(62.8)$ & $3(7.0)$ \\
\hline & Incorrect & $36(83.7)$ & $16(37.2)$ & $40(93.0)$ \\
\hline & Total & $43(100.0)$ & $43(100.0)$ & $43(100.0)$ \\
\hline \multicolumn{5}{|c|}{ Amongst those who stated drug name correctly: } \\
\hline & & $n=7(\%)$ & $n=27(\%)$ & $n=3(\%)$ \\
\hline Dose & Correct & $7(100.0)$ & $27(100.0)$ & $2(66.7)$ \\
\hline Frequency & Correct & $7(100.0)$ & $27(100.0)$ & $2(66.7)$ \\
\hline Duration & Correct & $7(100.0)$ & $27(100.0)$ & $2(66.7)$ \\
\hline \multirow{2}{*}{\multicolumn{2}{|c|}{$\begin{array}{l}\text { Management syndrome: GUS } \\
\text { (sexually active within the last } 3 \\
\text { months) }\end{array}$}} & \multicolumn{3}{|c|}{ Name of drug } \\
\hline & & Benzathine penicillin $n(\%)$ & Erythromycin $n(\%)$ & Acyclovir $n(\%)$ \\
\hline & Correct & $21(48.8)$ & $4(9.3)$ & $6(14.0)$ \\
\hline & Incorrect & $22(51.2)$ & $39(90.7)$ & $37(86.0)$ \\
\hline & Total & $43(100.0)$ & $43(100.0)$ & $43(100.0)$ \\
\hline \multicolumn{5}{|c|}{ Amongst those who stated the correct drug: } \\
\hline & & $n=21(\%)$ & $n=4(\%)$ & $n=6(\%)$ \\
\hline Dose & Correct & $21(100.0)$ & $4(100.0)$ & $5(83.3)$ \\
\hline Frequency & Correct & $21(100.0)$ & $4(100.0)$ & $5(83.3)$ \\
\hline Duration & Correct & $19(90.5)$ & $3(75.0)$ & $5(83.3)$ \\
\hline \multicolumn{5}{|c|}{$\begin{array}{l}\text { GUS (not sexually active within } \\
\text { the last } 3 \text { months) }\end{array}$} \\
\hline \multirow[t]{3}{*}{ Acyclovir } & Correct & 13 & 30.2 & \\
\hline & Incorrect & 30 & 69.8 & \\
\hline & Total & 43 & 100.0 & \\
\hline \multicolumn{5}{|c|}{ Amongst those who stated the correct drug $(n=13)$ : } \\
\hline Dose & Correct & 11 & 84.6 & \\
\hline Frequency & Correct & 10 & 76.9 & \\
\hline Duration & Correct & 11 & 84.6 & \\
\hline
\end{tabular}

graduated before or around 1994 when the national reference centre for STIs implemented the syndromic approach. Most of these doctors therefore already had the common perception that aetiological diagnosis can be made on clinical grounds alone.

These findings are supported by Schneider (1995), who assessed services for the control of sexually transmitted diseases in the Johannesburg, Pretoria and Vaal Triangle area, where $48.2 \%$ of the doctors interviewed indicated that they will treat for both

Table 6: Most effective source of information with regard to STI control, treatment of STIs and risk of HIV transmission

\begin{tabular}{lcc}
\hline Factor & $\begin{array}{c}\text { Frequency } \\
(n=43)\end{array}$ & $\begin{array}{c}\text { Percentage } \\
(\%)\end{array}$ \\
\hline $\begin{array}{l}\text { Single most effective source of } \\
\text { information to the public with regard } \\
\text { to control of STIs: }\end{array}$ & & \\
$\begin{array}{l}\text { Mass media (radio, television and } \\
\text { newspapers) }\end{array}$ & 25 & 61.0 \\
$\begin{array}{l}\text { Education by doctors and other } \\
\text { healthcare providers }\end{array}$ & 16 & 39.0 \\
$\begin{array}{l}\text { Appropriate treatment and control of } \\
\text { STls decreases the risk of HIV } \\
\text { transmission: }\end{array}$ & & \\
\hline $\begin{array}{l}\text { Agree } \\
\text { Disagree }\end{array}$ & 38 & 90.5 \\
\hline
\end{tabular}

gonococcal and non-gonococcal urethritis, or for the most likely causative organism, and routinely ask the patient to come back if symptoms persist. The remaining 51.8\% indicated

Table 7: Attitudes and perceptions of doctors towards SM guidelines

\begin{tabular}{|c|c|c|}
\hline Factor & Frequency & $\begin{array}{c}\text { Percentage } \\
\text { (\%) }\end{array}$ \\
\hline \multicolumn{3}{|c|}{$\begin{array}{l}\text { Doctors' satisfaction with the current } \\
\text { national SM guidelines for STIs }(n=39) \text { : }\end{array}$} \\
\hline Satisfied & 34 & 87.2 \\
\hline Not satisfied & 5 & 12.8 \\
\hline \multicolumn{3}{|c|}{$\begin{array}{l}\text { Doctors' interest in attending } \\
\text { continuing medical education seminars } \\
\text { on STI control }(n=42) \text { : }\end{array}$} \\
\hline Interested & 39 & 92.9 \\
\hline Not interested & 3 & 7.1 \\
\hline \multicolumn{3}{|c|}{ Doctors' STI management practices: } \\
\hline \multicolumn{3}{|l|}{ Diagnosis of STIs $(n=42)$ : } \\
\hline $\begin{array}{l}\text { Using only history and physical } \\
\text { examination }\end{array}$ & 22 & 52.4 \\
\hline $\begin{array}{l}\text { Using history, clinical evaluation, } \\
\text { microscopy and/or culture }\end{array}$ & 20 & 47.6 \\
\hline \multicolumn{3}{|c|}{$\begin{array}{l}\text { Asking questions about sexual practices } \\
(n=41) \text { : }\end{array}$} \\
\hline Yes & 35 & 85.7 \\
\hline No & 6 & 14.3 \\
\hline
\end{tabular}


Table 8: Doctors' practices with regard to STI prevention and health promotion

\begin{tabular}{lccc}
\hline Factor & $\begin{array}{c}\text { Always } n \\
(\%)\end{array}$ & $\begin{array}{c}\text { Sometimes } n \\
(\%)\end{array}$ & $\begin{array}{c}\text { Never } n \\
(\%)\end{array}$ \\
\hline $\begin{array}{l}\text { Asking patients about the } \\
\text { number of sexual partners } \\
(n=42)\end{array}$ & $7(16.7)$ & $30(71.4)$ & $5(11.9)$ \\
$\begin{array}{l}\text { Examination of the } \\
\text { genitals of patients } \\
\text { suffering from STIs }(n=42)\end{array}$ & $23(54.8)$ & $18(42.8)$ & $1(2.4)$ \\
$\begin{array}{l}\text { Filling of the partner } \\
\text { notification slips after } \\
\text { attending to the index } \\
\text { patient }(n=42)\end{array}$ & $4(9.5)$ & $32(76.2)$ & $6(14.3)$ \\
$\begin{array}{l}\text { Counselling for HIV testing } \\
(n=41)\end{array}$ & $21(51.2)$ & $20(48.8)$ & $0(0)$ \\
\hline
\end{tabular}

they will treat with only one drug or treat based on clinical diagnosis. ${ }^{20}$ Since one-quarter of gonococcal infections are clinically indistinguishable from non-gonococcal urethritis, it therefore means the above treatments are definitely inadequate. ${ }^{14}$

\section{Adherence practices to the STI guidelines}

In order to treat patients with STIs using the best available evidence, healthcare providers have to follow the national SM guidelines. ${ }^{5}$ Only one $(2.3 \%)$ of the respondents gave correct answers to all the knowledge questions, including correct adherence to the guidelines for all the STI syndromes assessed. It seems that clinicians are not using the guidelines when they prescribe medications, despite the fact that the guidelines can easily be accessed through the Internet and in many instances are available in the consulting rooms. Non-adherence of doctors to guidelines is thought to contribute significantly to poor delivery of clinical care, resulting in poor clinical outcomes. ${ }^{11}$ In a study done in the Bojanala district of South Africa overall adherence of doctors to treatment guidelines for hypertension was found to be low $(51.9 \%){ }^{20}$ Similar to the finding in the current study, the Bojanala study also found that the low adherence rates were related to age (older doctors) and the rates of adherence also differed with regard to various aspects of the guidelines. ${ }^{11}$ In a study done in South Ethiopia only in $8.3 \%$ of cases did the clinicians correctly adhere to the national SM guidelines for STIs; the majority used their experience to treat STI patients. ${ }^{19}$ In a study conducted in six countries in West Africa, correct treatment was given to only $14.1 \%$ of patients according to the national syndromic STI management algorithms. ${ }^{18}$

Many respondents ( 22 or $52.4 \%$ ) made the diagnosis of STI syndromes using only history and physical examination of the patient according to the national syndromic STIs management guidelines. This is higher than in other studies using similar study methods in Pakistan and Vietnam, which showed that only $31 \%$ and $25 \%$ respectively of their doctors made the diagnosis using history and physical examination. ${ }^{21,22}$ In other parts of sub-Saharan Africa primary health care doctors also show poor STI management practices with inadequate history taking, clinical examination and prescriptions. ${ }^{23}$

Only seven (16.7\%) of the respondents always asked about number of sexual partners. This is lower than found in a study in Karachi, Pakistan, in which $78 \%$ of the doctors asked their patients about their number of sexual partners. ${ }^{21}$ Our study showed that 21 (51.2\%) of the respondents always counsel/ screen patients with STIs for HIV infection. This is slightly

Table 9: Doctors' knowledge, attitudes and practices by sex and age

\begin{tabular}{|c|c|c|c|c|c|}
\hline Factor & & $\begin{array}{l}\text { Good/optimal } \\
(>70 \%)\end{array}$ & $\begin{array}{l}\text { Satisfactory/average } \\
(40-70 \%)\end{array}$ & $\begin{array}{l}\text { Poor/suboptimal } \\
(<40 \%)\end{array}$ & $p$-value \\
\hline \multicolumn{6}{|c|}{ Doctors' knowledge: } \\
\hline \multirow[t]{2}{*}{ Sex } & Female & $2(10.0)$ & $17(85.0)$ & $1(5.0)$ & 0.267 \\
\hline & Male & $5(21.7)$ & $14(60.9)$ & $4(17.4)$ & \\
\hline \multicolumn{6}{|c|}{ Doctors' attitude } \\
\hline \multirow[t]{2}{*}{ Sex } & Female & $19(95.0)$ & $0(0.0)$ & $1(5.0)$ & 0.465 \\
\hline & Male & $23(100.0)$ & $0(0.0)$ & $0(0.0)$ & \\
\hline \multicolumn{6}{|c|}{ Doctors' practice } \\
\hline \multirow[t]{2}{*}{ Sex } & Female & $1(5.0)$ & $13(65.0)$ & $6(30.0)$ & 0.861 \\
\hline & Male & $0(0.0)$ & $16(69.6)$ & 7 (30.4) & \\
\hline \multicolumn{6}{|c|}{$\begin{array}{l}\text { Doctors' knowledge, attitudes and } \\
\text { practices in relation to their age: }\end{array}$} \\
\hline \multicolumn{6}{|c|}{ Doctors' knowledge: } \\
\hline \multirow[t]{3}{*}{ Age (years) } & $20-29$ & $1(14.3)$ & $6(85.7)$ & $0(0.0)$ & $0.005^{\mathrm{a}}$ \\
\hline & $30-39$ & $5(20.0)$ & $20(80.0)$ & $0(0.0)$ & \\
\hline & $40-49$ & $1(9.1)$ & $5(45.5)$ & $5(45.5)$ & \\
\hline \multicolumn{6}{|c|}{ Doctors' attitude: } \\
\hline \multirow[t]{3}{*}{ Age (years) } & $20-29$ & $7(100.0)$ & $0(0.0)$ & $0(0.0)$ & 1.000 \\
\hline & $30-39$ & $24(96.0)$ & $0(0.0)$ & $1(4.0)$ & \\
\hline & $40-49$ & $11(100.0)$ & $0(0.0)$ & $0(0.0)$ & \\
\hline \multicolumn{6}{|c|}{ Doctors' practice: } \\
\hline \multirow[t]{3}{*}{ Age (years) } & $20-29$ & $1(14.3)$ & $4(57.1)$ & $2(28.6)$ & 0.471 \\
\hline & $30-39$ & $0(0.0)$ & $17(68.0)$ & $8(32.0)$ & \\
\hline & $40-49$ & $0(0.0)$ & $8(72.7)$ & $3(27.3)$ & \\
\hline
\end{tabular}

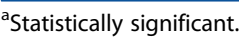


higher than the $44 \%$ obtained in the study done in Pakistan. ${ }^{21}$ Some studies showed that doctors reported lack of time to offer HIV counselling and testing to patients as a barrier. ${ }^{24-26}$ Only $4(9.5 \%)$ of the respondents always filled in the notification slips, while 32 (76.2\%) of the respondents sometimes filled them in. Some studies found that doctors complain about lack of time and of appropriate sexual health counselling skills as barriers to conducting sexual history taking and/or discussing sexual health issues with patients. ${ }^{27-29}$ However, in order to treat STIs comprehensively, follow the guidelines and prevent reinfection, it is imperative to counsel the patient and to treat the contact sexual partners. ${ }^{14}$ A study in Hlabisa, KwaZulu-Natal showed that only $9 \%$ of patients received comprehensive syndromic management. $^{30}$

Based on the above results, it is seen that training in STI clinical case management is still essential and that there is a need for efforts to ensure that every primary level clinical care provider knows and understands the syndromic case management protocols, which are regularly updated according to changing trends of STIs. ${ }^{31}$ Postgraduation training is essential for comprehensive treatment of all STI syndromes. ${ }^{32}$ A study in Abidjan, Ivory Coast showed that healthcare providers who recently received STI training scored significantly better than those who did not. ${ }^{33}$ However, other studies have shown that clinicians' training and knowledge does not ensure practice consistent with recommended guidelines. A study conducted in Canada found that adherence to Centres for Disease Control guidelines did not improve with additional training. ${ }^{34}$ It has also been found that adherence to clinical guidelines is difficult to achieve even when this is intensively promoted. ${ }^{35}$

\section{Conclusion}

In general the knowledge, attitudes and practices of doctors in Jubilee District Hospital regarding SM guidelines for STIs were suboptimal. Older doctors had suboptimal knowledge, attitudes and practices of the SM guidelines for STIs.

This emphasises the need for further intensive training of healthcare providers to improve their ability to diagnose and treat patients infected by STIs correctly according to the national guidelines. This is essential as control and appropriate treatment of STIs impact on prevention of HIV spread.

Preparation and provision/availability of clinical treatment guidelines for STIs are not enough. There should be well-structured plans for the continuous training of doctors, especially for those doctors older than 40 years, on the SM of STIs. This should be followed by post-training supportive supervision to monitor and evaluate the actual performance of the doctors from time to time.

\section{Recommendations}

Undergraduate training for doctors on STI management should always be in line with the national treatment guidelines. In addition, the content and method of teaching should encourage SM. Post-qualification monitoring and evaluation is also recommended to ensure compliance with the SM guidelines for STIs.

\section{Limitations of the study}

The study was carried out in one public hospital and may not necessarily be representative of all South African doctors.

Disclosure statement - No conflict of interest was reported by the authors.

\section{References}

1. Newman L, Rowley J, Vander Hoorn S, et al. Global estimates of the prevalence and incidence of four curable sexually transmitted infections in 2012 based on systematic review and global reporting. Plos One Med. 2015 Dec 8. Available from: http://journals.plos.org/ plosone/article?id=10.1371/journal.pone.0143304

2. World Health Organization (WHO). Global incidence and prevalence of selected curable sexually transmitted infections - 2008. World Health Organization. 2012. http://www.who.int/iris/handle/10665/ 75181

3. Sonko R, Mccoy D, Gosa E, et al. An overview of issues on STI management and control in South Africa. Durban: Health Systems Trust; 2003.

4. Jubilee District Hospital. Data from outpatient department records, 2013. Temba: City of Tshwane Municipality, Gauteng Province South Africa.

5. Federal Democratic Republic of Ethiopia, Ministry of Health, Addis Ababa. HIV/AIDS prevention and control office, national guidelines for the management of sexually transmitted infections using the syndromic approach. Addis Ababa: FDRE; 2015.

6. Costello-Daly C, Franco L, Chilongozi DAT, et al. A cost comparison of approaches to sexually transmitted disease treatment in Malawi. Health Policy Plann. 1998;13(1):87-93.

7. World Health Organization. Global incidence and prevalence of selected curable sexually transmitted infections. Geneva: World Health Organization; 2013; 5.

8. Wasserheit JN. Inter-relationships between human immunodeficiency virus infection and other sexually transmitted diseases. Epidemiol Synergy. 1992;19:261.

9. Bosu WK. Syndromic management of sexually transmitted diseases: is it rational or scientific? Trop Med Int Health. 1999;4:114-9. doi:10. 1046/j.1365-3156.1999.00360.x

10. Ham DC, Hariri S, Kamb M, et al. Quality of sexually transmitted infection case management services in Gauteng Province, South Africa: An evaluation of health providers' knowledge, attitudes, and practices. Sex Transm Dis. 2016;43(1):23-29.

11. Adedeji AR, Tumbo J, Govender I. Adherence of doctors to a clinical guideline for hypertension in Bojanala district, North-West Province, South Africa. PHCFM. 2015;7(1):6.

12. Jubilee Hospital Information Management Office. Jubilee district hos pital. Temba: City of Tshwane Municipality, Gauteng Province, South Africa; 2013.

13. Connolly AM, Wilkinson D, Harrison A, et al. Inadequate treatment for sexually transmitted diseases in the South African private health sector. Int J STD AIDS. 1999;10(5):324-7.

14. Ballard R, Htun Y, Fenhler $G$, et al. The diagnosis and management of sexually transmitted infections in southern Africa. 3rd ed. Johannesburg: South African Institute for Medical Research; 2000.

15. Dangor Y, Ballard RC, Exposto FDL, et al. Accuracy of clinical diagnosis of genital ulcer disease. Sex Transm Dis. 1990;17(4):184-9.

16. O'Farrel N, Hoosen AA, Coetzee KD, et al. Genital ulcer disease: Accuracy of clinical diagnosis and strategies to improve control in Durban, South Africa. Genitourin Med. 1994;70:7-11.

17. Lipinge SN, Pretorius L. The delivery and quality of sexually transmitted infections treatment by private general practitioners in Windhoek Namibia. Global J Health Sci. 2012;4(5):156-71.

18. Bitera R, Alary M, Mâsse B, et al. Quality of disease management of sexually transmitted diseases: investigation of care in six countries in West Africa. Cahiers Sante. 2002;12(2):233-9.

19. Alemayehu A, Godana W. Knowledge and practice of clinicians regarding syndromic management of sexually transmitted infections in public health facilities of Gamo Gofa Zone, South Ethiopia. J Sex Transm Dis. 2015;2015:1-6. doi:10.1155/2015/310409

20. Schneider H. Assessment of Services for the control of sexually transmitted diseases in the PWV province. Technical Report Johannesburg: Centre for Health Policy, University of the Witwatersrand; 1995.

21. Khandwalla HE, Luby S, Rahman S. Knowledge, attitudes, and practices regarding sexually transmitted infections among general practitioners and medical specialists in Karachi, Pakistan. J Sex Transm Infect. 2000;76:383-5. 
22. Lan PT, Mogren I, Phuc HD, et al. Knowledge and practice among healthcare providers in rural Vietnam regarding sexually transmitted infections. J Sex Trans Infect. 2009;36(7):452-8.

23. Boonstra $E$, Lindbæk M, Klouman $E$, et al. Syndromic management of sexually transmitted diseases in Botswana's primary health care: quality of care aspects. Trop Med Int Health. 2003;8:604-614.

24. Do K, Minichiello V, Hussain R, et al. Physicians' perceived barriers to management of sexually transmitted infections in Vietnam. BMC Publ Health. 2014;14:110. doi:10.1186/1471-2458-14-1133

25. Lugtenberg M, Zegers-van Schaick JM, Westert GP, et al. Why don't physicians adhere to guideline recommendations in practice? An analysis of barriers among Dutch general practitioners. Implement Sci. 2009;4:54

26. White BL, Walsh J, Rayasam S, et al. What makes me screen for HIV? Perceived barriers and facilitators to conducting recommended routine HIV testing among primary care physicians in the Southeastern United States. J Int Assoc Provid AIDS Care. 2014; doi:2325957414524025

27. Barber B, Hellard M, Jenkinson R, et al. Sexual history taking and sexually transmissible infection screening practices among men who have sex with men: A survey of Victorian general practitioners. Sex Health. 2011;8:349-54.

28. Dyer K, das Nair R. Why don't healthcare professionals talk about sex? A systematic review of recent qualitative studies conducted in the United Kingdom. J Sex Med. 2013;10:2658-70.
29. Carter JW, Hart-Cooper GD, Butler MO, et al. Provider barriers prevent recommended sexually transmitted disease screening of HIVinfected men who have sex with men. Sex Transm Dis. 2014;41:137-42.

30. Wilkinson D, Abdool Karim SS, Lurie M, et al. Public-Private health sector partnerships for STD control in South Africa: Perspectives from the Hlabisa experience. SAMJ. 2001;91(6):17-20.

31. Lehmann U, Sanders D. Human resource development. South African health review. Durban: Health Systems Trust; 2002. p. 119-133.

32. Ndhlovu L, Searle C, van Dam J, et al. Reducing transmission of HIV and sexually transmitted infections in a mining community. Findings from the Carltonville Mothusimpilo intervention project: 1998 to 2001 "Horizons" Final Report. Washington, DC: Population Council; 2005.

33. Vuylsteke B, Traore M, Mah-Bi G, et al. Quality of sexually transmitted infections services for female sex workers in Abijan, Cote d'Ivoire. Trop Med Int Health. 2004;9(5):638-43.

34. Ellrodt AG, Connor L, Riedinger $M$, et al. Measuring and Improving Physician Compliance with Clinical Practice Guidelines: A Controlled Interventional Trial. Ann Intern Med. 1995;122:277-82.

35. Mak DB, Holman DJ. STDs aren't sexy: health professionals' lack of adherence to clinical guidelines in an area of high STD endemicity. J Public Health. 2000;22(4):540-5.

Received: 12-04-2018 Accepted: 6-06-2018 